\title{
Spatio-temporal variability in Posidonia oceanica seagrass meadows of the Western Mediterranean: shoot density and plant features
}

\author{
Claudio Vasapollo ${ }^{1,2, *}$, Maria Cristina Gambi ${ }^{1}$ \\ ${ }^{1}$ Stazione Zoologica Anton Dohrn, Functional and Evolutionary Ecology Laboratory, Naples 80121, Italy \\ ${ }^{2}$ National Research Council of Italy (CNR), Marine Sciences Institute (ISMAR), Ancona 60125, Italy
}

\begin{abstract}
The spatial and temporal variability of shoot density and selected plant features of Posidonia oceanica seagrass were assessed in 2 different meadows off the Island of Ischia (Naples, Italy), subjected to different degrees of both human impact and hydrological conditions. A nested hierarchical sampling design was used (1) to examine patterns of distribution of shoot density and plant features at different spatial scales and (2) to analyze temporal patterns of variability along the 2 principal seasons, showing the minimum and maximum development of the plant canopy (summer and winter; 2 sampling dates for each season). The shoot density showed 2 main spatial scales of variability: between the 2 beds (a few km apart) and within each meadow (10s of m); however, there were no seasonal differences. Most morphometric features showed multiple spatial scales of variability, especially at the smallest scale $(10 \mathrm{~s}$ of $\mathrm{cm})$, but none of these parameters varied significantly between the meadows. Most of the morphometric parameters also displayed variations with season and date of sampling, likely related to the growth cycle of the plant. A permutational analysis of variance identified several scales of variability for all features across the suite of scales from 10 s to 100 s of meters and for seasons and sampling dates. The present study provides evidence of the high spatio-temporal variability of $P$. oceanica plant features despite the different ecological status of the meadows. It is advisable to take this high variability into account during monitoring studies to avoid misinterpretation of natural variation.
\end{abstract}

KEY WORDS: Posidonia oceanica $\cdot$ Seagrass $\cdot$ Mediterranean Sea $\cdot$ Hierarchical sampling design · Nested ANOVA $\cdot$ PERMANOVA $\cdot$ Spatial variability $\cdot$ Temporal variability

Resale or republication not permitted without written consent of the publisher

\section{INTRODUCTION}

The problem of understanding patterns and scales has been a central issue in ecology for a long time (Levin 1992). As Wiens (1989) noted, 'scale' has rapidly become a new ecological 'buzzword', a fashionable word that led to the development of new statistical instruments to investigate communities and species distribution (e.g. Underwood 1992, Anderson 2001a).

In the last few decades, ecologists have become more interested in the influence of scale-dependent processes on communities. Within the marine ecology discipline, there has been an expanded applica- tion of the scaling-effects concept in the experimental design and interpretation of surveys, which has led to the production of a great amount of literature (Dayton \& Tegner 1984, Wiens et al. 1986, Frost et al. 1988, Kotliar \& Wiens 1990, Levin 1992, Fraschetti et al. 2005, Boström et al. 2006).

From the available literature related to the marine benthic biota (see review by Fraschetti et al. 2005), a common general picture emerges across various habitat scales: i.e. small- (10s to $100 \mathrm{~s}$ of $\mathrm{cm}$ ) and intermediate-scale (10s to $100 \mathrm{~s}$ of $\mathrm{m}$ ) variation in the distribution and abundance of single species and communities is often greater than large-scale variation. 
Thus, small-scale spatial variability, often still considered simply as a 'statistical nuisance' due to stochastic events, is becoming of great interest because it is seen as the result of specific local processes.

Knowledge of the appropriate scale of spatial and temporal variability is essential to discriminate between natural and anthropogenic disturbances. Degradation often operates on increasing 'heterogeneity' (i.e. patchiness) across scales and reducing 'complexity' (e.g. shoot density or coverage in seagrass systems). Thus, changes in small-scale variability have been often proposed as a diagnostic feature for disturbed marine communities.

The endemic seagrass Posidonia oceanica (L.) Delile, one of the most common and widespread macrophytes found in the Mediterranean Sea, covers between 2.5 and 5.5 million ha of soft and rocky substrates within the Mediterranean, along depth ranges from $<1$ to $>40 \mathrm{~m}$ (Procaccini et al. 2003, Ruiz et al. 2009). P. oceanica meadows represent one of the most productive and complex shallow coastal ecosystems in the Mediterranean Sea (Vizzini 2009) and provides several ecosystem services, such as supporting a large biodiverse (floral and faunal) community by acting as a nursery and feeding grounds for many commercially important species (Mazzella et al. 1992).

Posidonia oceanica, as a 'habitat engineer' and because of its often extensive meadows, has been included among the environmental quality descriptors in the European Water Directive (Lopez y Royo et al. 2010a); thus, the importance of understanding the processes that link local to regional scales in $P$. oceanica meadows is relevant for monitoring programs designed to estimate the health of a system and to determine when protection measures need to be taken, especially in light of the global recognition of the decline in seagrasses worldwide (Orth et al. 2006, Boudouresque et al. 2009, Waycott et al. 2009). Investigations of the status of $P$. oceanica meadows along the Mediterranean marine protected areas (MPAs) found no widespread habitat decline (González-Correa et al. 2007), suggesting anthropogenic impacts (such as boat anchoring, trawling and coastal development) may be responsible for localized P. oceanica meadow decline (Ruiz \& Romero 2003, Milazzo et al. 2004, Leriche et al. 2006, Montefalcone et al. 2008b). Thus, the establishment of MPAs may need to be considered as possible mitigation for the decline of meadows seen over the last several decades. However, Montefalcone et al. (2009) suggest that the establishment of local MPAs may not reduce regional scale effects because factors driving the reduction of $P$. oceanica may originate outside MPA boundaries. Studies by González-Correa et al. (2007) and Montefalcone et al. (2009) are clear examples of how the possible protection of this system requires the understanding of the principal growth patterns along several spatial and temporal scales (Boström et al. 2006). Moreover, differences in monitoring strategies, sampling designs and methods affect the reliability of the collected data and consequently the data comparability (Lopez y Royo et al. 2010b).

Most published studies on the spatial variability of Posidonia oceanica focus on variations across large scales (100s to 1000 s of meters) or within meadows across depth gradients (e.g. shallow vs. deep stands), but few studies have examined variations within a meadow at medium and small scales (from $10 \mathrm{~s}$ of $\mathrm{cm}$ to $10 \mathrm{~s}$ of $\mathrm{m}$ ) or at a given depth. However, those studies that have (Balestri et al. 2003, Zupo et al. 2006a,b, Montefalcone et al. 2008a) demonstrate that P. oceanica meadows are characterized by high patchiness in shoot density and some plant attributes at intermediate (from 10s to 100 s of meters) and small (few meters) spatial scales (Balestri et al. 2003, Kendrick et al. 2005, Zupo et al. 2006b), so there is the risk that previous studies conducted across large spatial scales have generalized the variability of small-scale patchiness.

Heterogeneity has also been seen to increase at smaller scales when companion epiphytic (leaf- and rhizome-associated) communities have been studied (Piazzi et al. 2004, Pardi et al. 2006, Balata et al. 2007), despite the apparent homogeneity of the system at larger scales. This variability has been explained by differences in shoot density and in characteristics of the canopy affecting light intensity, water movements and nutrient availability.

The present study is part of a larger project aimed at evaluating the dynamics of spatial and temporal morphometric patterns, specifically shoot density and other plant attributes, as well as of some associated invertebrates (motile fauna and borer organisms) within Posidonia oceanica meadows under different ambient conditions, using a nested hierarchical sampling design. Herein, we discuss (1) morphometric patterns of spatial variability, across scales, in $2 P$. oceanica meadows off the coasts of the island of Ischia (Tyrrhenian Sea, Italy) subjected to differing structuring factors and (2) seasonal patterns of development and growth of the plant canopy (summer and winter), and (3) we compare our data with previous results obtained with a different sampling design. We hypothesized that heterogeneity across scales and variables would increase as disturbance level increases. 


\section{MATERIALS AND METHODS}

\section{Study area}

Sampling was conducted within 2 Posidonia oceanica meadows on either side of the island of Ischia (Thyrrenian Sea, Gulf of Naples, Italy; Fig. 1). Both meadows have been thoroughly studied (Buia et al. 2003, Gambi \& Buia 2003, Lorenti et al. 2005, Zupo et al. 2006a,b) and were first mapped by Colantoni et al. (1982); other surveys are reported by Buia et al. (2003). Historic data reveal the distinct differences between the 2 meadows, with the meadow of Lacco Ameno (LA), on the northern side of the island, influenced by various anthropogenic impacts and pressures, while the meadow of Scarrupata ( $\mathrm{Sc}$ ), on the south-east side of the island, is still relatively pristine with little anthropogenic impact.

The LA site is protected from the major currents and wave actions by the island, which has resulted in the meadow growing from $0.5 \mathrm{~m}$ to $28-32 \mathrm{~m}$ depth. The LA meadow has been widely studied since 1979 and has demonstrable progressive deterioration with a decrease in shoot density over time (Buia et al. 2003, Zupo et al. 2006a,b and references therein). The Posidonia oceanica decline in the LA can likely be attributed to the increasing turbidity resulting from the periodic dumping of sludge (Guidetti \& Fabiano 2000) and the output of 2 sewage pipes, which handled the sewage of 2 towns (Lacco Ameno and Casamicciola) with a combined resident population of $\sim 11000$, which strongly increases during the summer tourist season (Zucco 2003). In addition, the LA meadow is heavily utilized by pleasure boats that

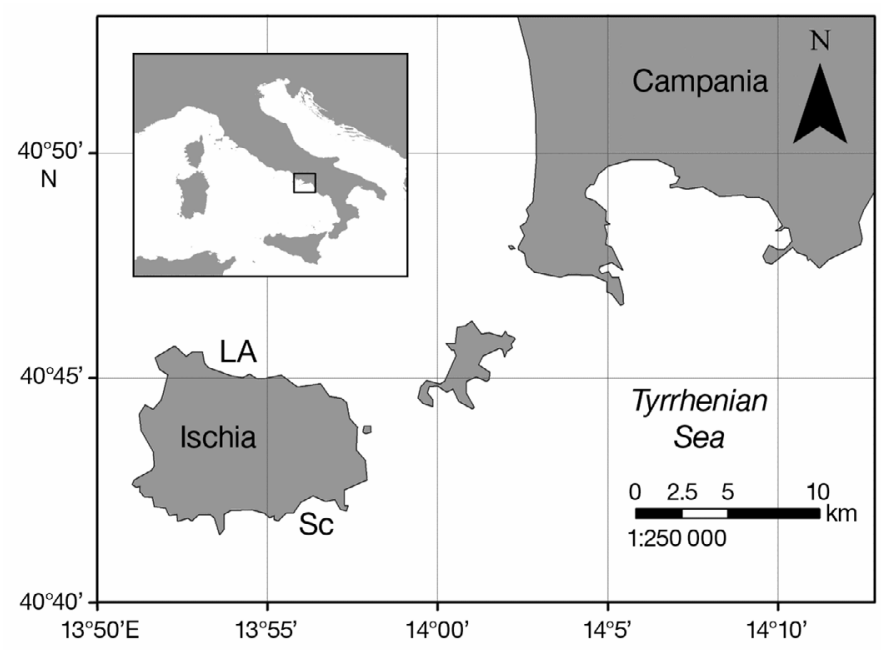

Fig. 1. Location of the sampling areas off the island of Ischia (Tyrrhenian Sea, Italy). LA: Lacco Ameno, Sc: Scarrupata are anchored in the protected waters, especially during the summer season.

The Sc meadow, located $\sim 10 \mathrm{~km}$ from LA, within a large bay along the southern coast, does not have urban shorelines yet is much more exposed to southerly currents and wave action. This meadow begins at a depth of 8 to $10 \mathrm{~m}$, reaching a maximum depth of $35 \mathrm{~m}$, and is sharply demarcated, a characteristic of strong bottom currents. This meadow has a relatively uniform plant distribution except for a few discontinuities (scarcely covered patches) at 15 and $20 \mathrm{~m}$ and between 25 and $30 \mathrm{~m}$. Shoot density measured regularly at 10 and $30 \mathrm{~m}$ since 1996 (Buia et al. 2003) shows a degree of variability (patchiness) at $10 \mathrm{~m}$ with a slight decrease recorded over the period of record. In comparison, at $30 \mathrm{~m}$, the shoot density is more constant, displaying a slight increase over the period of record (Buia et al. 2003, Lorenti et al. 2005).

\section{Sampling design}

The sample design was intended to study plant morphometrics (i.e. shoot density, leaf length and width, leaf biomass and number of leaves). A hierarchical, nested sampling design (Fig. 2) was used to test the null hypothesis that shoot density and plant features did not vary at different spatial and temporal scales. For each of the 2 meadows, 3 randomly selected sites were chosen at a distance of at least $180 \mathrm{~m}$ apart; for each site, 2 stations were randomly selected $\sim 25 \mathrm{~m}$ apart; for each station, 3 plots were randomly located $3 \mathrm{~m}$ apart; for each plot, two $40 \times$ $40 \mathrm{~cm}$ quadrats were placed $1 \mathrm{~m}$ apart. Sampling was

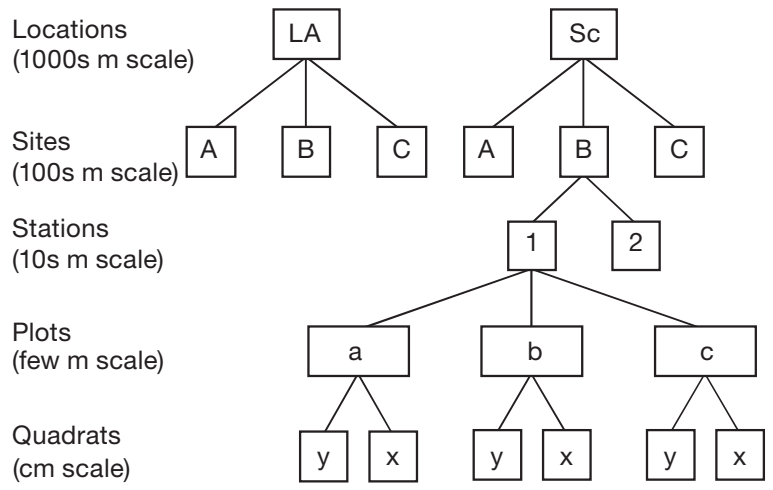

Fig. 2. Hierarchical sampling design utilized in the present study: two $40 \times 40 \mathrm{~cm}$ quadrats ( $\mathrm{x}$ and y) located $1 \mathrm{~m}$ apart, nested within each of 3 plots $(a, b, c)$ separated by $3 \mathrm{~m}$, nested within each of 2 random stations $(1,2)$ separated by $25 \mathrm{~m}$, nested within each of 3 sites (A, B, C) separated by $\sim 180 \mathrm{~m}$, nested within each of 2 Posidonia oceanica meadows located along the northern (LA) and southern (Sc) shorelines 
conducted at a depth range of 15 to $17 \mathrm{~m}$ to limit variability that might be attributed to depth differences and to better evaluate horizontal variability (Balestri et al. 2003). This depth range was selected based on previous studies that showed that the main plant features were relatively homogeneous relative to other depths, and the associated assemblages more abundant and the most characteristic of the system (Mazzella et al. 1989, Gambi et al. 1992).

Samples were collected over 2 seasons: late spring/ summer 2007 and late autumn/winter 2007-2008, representing the maximum and the minimum in the plant features and canopy development, respectively (Buia et al. 1992). This did not represent a seasonality per se but only the analysis of the plant features in 2 contrasting temperature and seasonal conditions. For each season and meadow, the sampling was repeated twice: in May, July, November/December and February in Lacco Ameno; and in June, September, December/January and March in Scarrupata.

In each quadrat, all shoots (vertical and horizontal) were enumerated, and 10 vertical (ortothropic) shoots were collected and stored in a $4 \%$ seawater buffered formalin solution for morphometric analysis. Leaf morphology and leaf biomass were measured according to standard analytical methods (Buia et al. 2004) with a mean calculated for each variable for each quadrat. Leaf biomass (dry weight) was measured after drying the leaves at $60^{\circ} \mathrm{C}$ in an oven until constant weight was reached.

\section{Statistical analysis}

Univariate nested analysis of variance (ANOVA) was used to statistically test for shoot-density and plant-feature variance across scales (spatial and temporal). The Student-Newman-Keuls (SNK) test was performed a posteriori whenever a significant difference was found. The Cochran's C test was performed as an a priori evaluation of homogeneity of variance. When the test was significant ( $p<0.05)$, a more stringent criterion of $\alpha=0.01$ was applied to avoid Type I errors (Underwood 1997). To determine which spatial scales were associated with the greatest variability, components of each spatial scale's variance were estimated (Underwood 1997). Negative variance components were converted to 0 because they likely were underestimated samples of small or 0 variances (Underwood 1997).

Permutational multivariate analysis of variance (PERMANOVA; Anderson 2001a) using the same statistical design as above was employed to test the hypothesis that the plant-features distribution across scales differed between the 2 meadows. This procedure is based on a Euclidean distance matrix calculated using standardized data (z-score). To calculate the probability that 2 variances were, or were not, significantly different, each term was tested using 4999 permutations; when this number of possible permutations was too low to get a reasonable test, the Monte Carlo procedure was used (Anderson 2001b).

A graphical representation of the multivariate patterns was obtained by employing non-metric multidimensional scaling (nMDS), based also on a Euclidean distance matrix calculated from raw data after standardizing (z-score). Graphically, the data plotted were centroid depicting location, site, season and date, which permitted the best visualization of the patterns displayed by the variable distributions (Anderson 2001a, McArdle \& Anderson 2001, Anderson \& Willis 2003). The data were plotted as a bi-plot where the Pearson's r correlations for each variable defined the 2 main nMDS axis.

\section{RESULTS}

Shoot density and all plant variables showed significant differences of their means for at least $1 \mathrm{spa}-$ tial scale studied and commonly at multiple scales. All variables also showed significant differences for at least 1 temporal scale studied (dates of sampling and season), with the exception of the shoot density.

Among the structural variables, shoot density (Figs. $3 \& 4$ ) varied only at the largest spatial scale (few $\mathrm{km}$ apart) and at the intermediate scale (10s of m) (Table 1). The main station-level differences (SNK, $\mathrm{p}<0.05$ ) were likely caused by the strong variability at $\mathrm{Sc}$ during winter. Differences in shoot density through time (seasons and dates) were not evident.

In both meadows, all of the plant features differed on the smallest spatial scale of quadrat (Table 2). The mean number of leaves per shoot, and similarly the mean number of adult leaves per shoot, varied only at the quadrat scale (Table 2). Although the mean values of both variables were not significantly different between the 2 meadows, both varied with the date of sampling (Table 2), with the mean number of leaves and adult leaves per shoot always greater during the second date of sampling in summer for both meadows, while the contrary was evident in winter (SNK, p < 0.01).

The mean number of intermediate leaves per shoot varied at the 2 smallest spatial scales (i.e. quadrat and plot) (Table 2). The intermediate leaves reached 

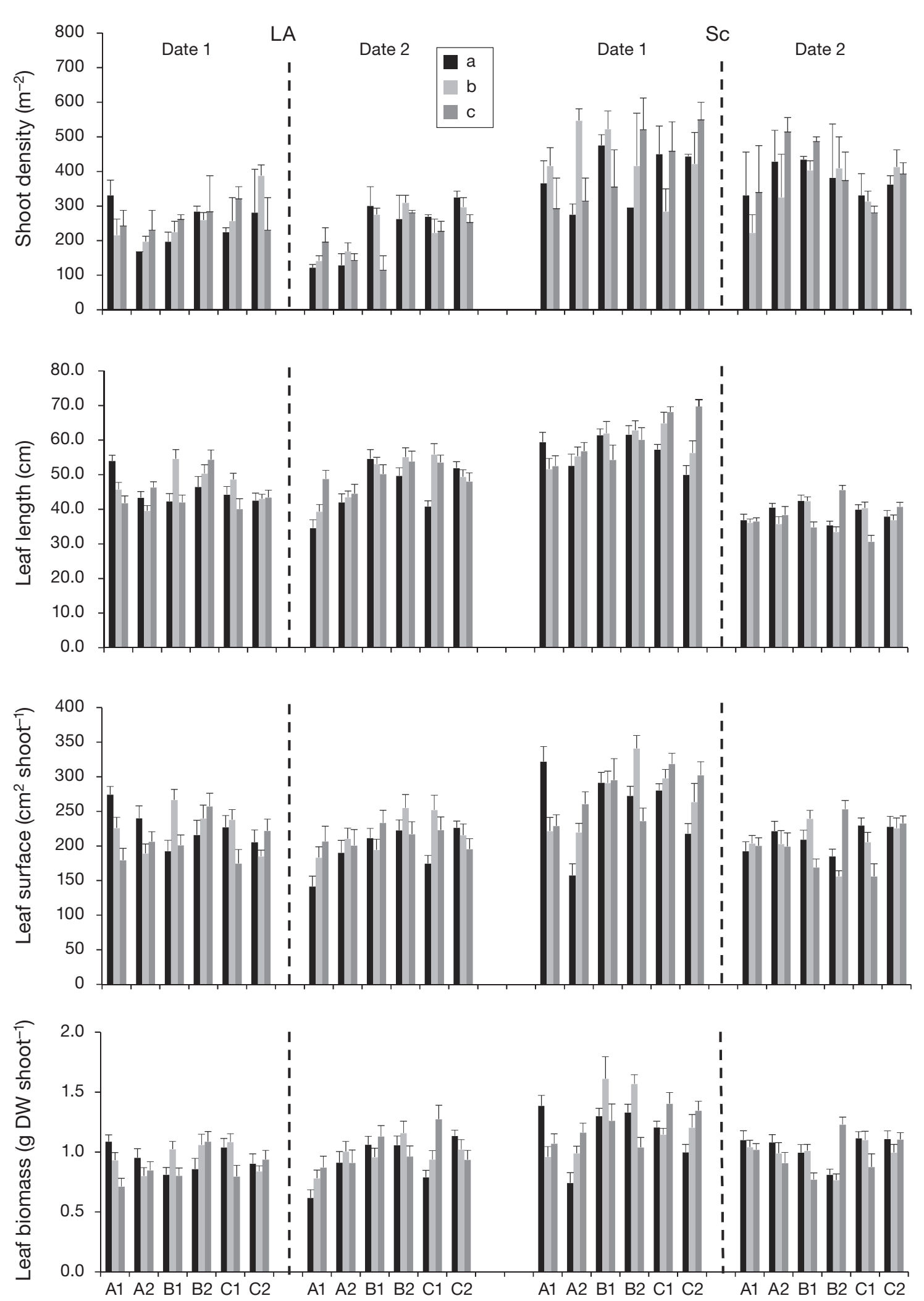

Fig. 3. Posidonia oceanica. Main descriptors of LA and Sc meadows at the plot scale (few meters; a, b, C; data pooled from 2 quadrats per plot) with corresponding station $(1,2)$ and site $(A, B, C)$ on both sampling dates during late spring/summer. The mean + SE are given for shoot density, leaf length, leaf surface and leaf biomass. First date: May 2007 for LA, June 2007 for Sc; second date: July 2007 for LA, September 2007 for Sc. DW = dry weight 

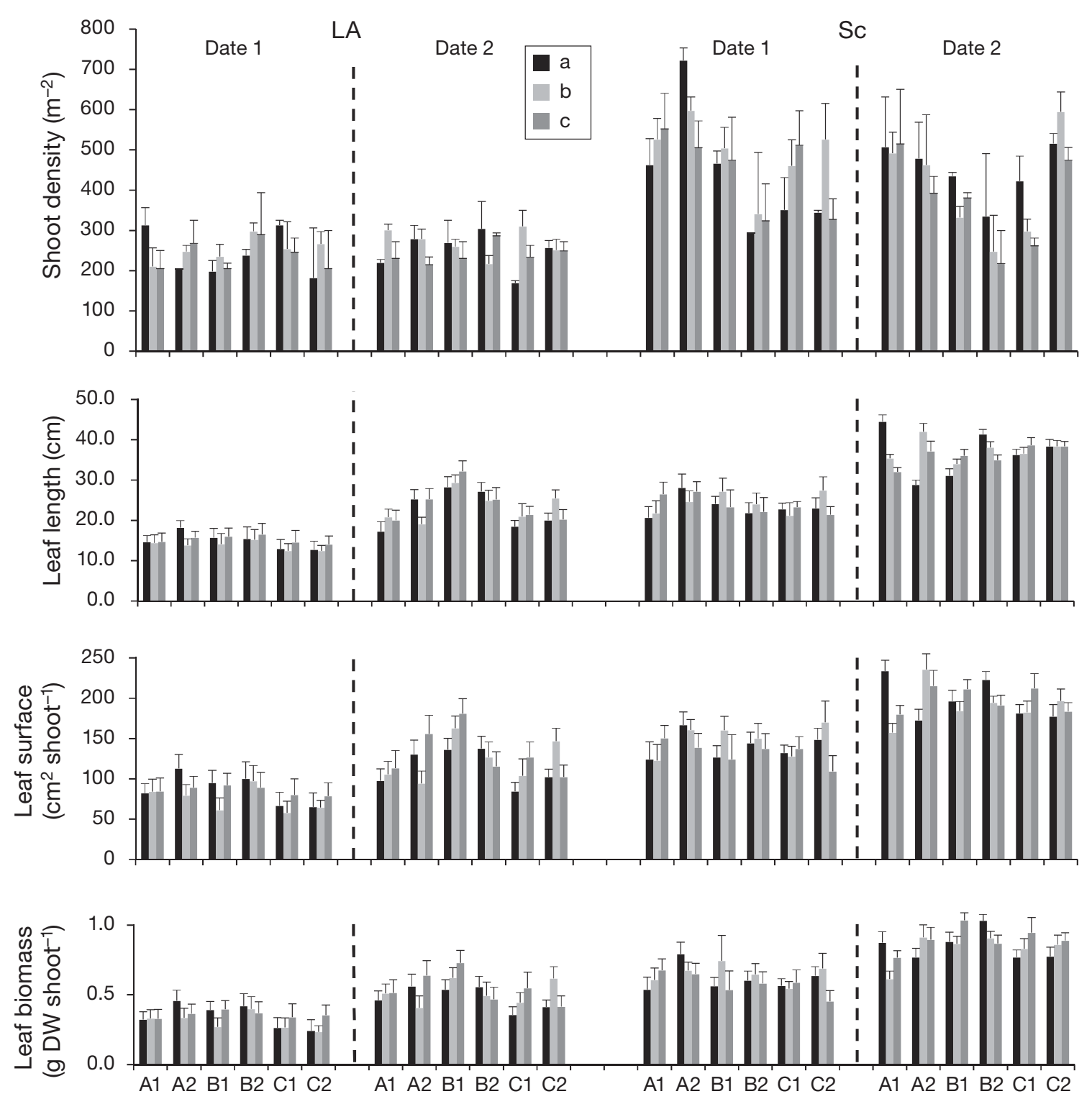

Fig. 4. Posidonia oceanica. Main descriptors of LA and Sc meadows during autumn/winter. Additional details as in Fig. 3

their maximum number in winter for both meadows but showed differences according to the date of sampling. Specifically, higher values were observed on the second date of summer sampling, while in winter, the opposite was observed at Sc (SNK, p < 0.05); the opposite trend was observed at LA (SNK, $\mathrm{p}<0.05)$.

The mean number of juvenile leaves per shoot varied at the smallest spatial scale as well as with the date of sampling (Table 2). For both meadows, the highest values were recorded at the second summer sampling, while during winter, the first sampling date showed the highest values (SNK, $p<0.05$ ). The mean leaf length (Figs. $3 \& 4$ ) varied significantly at the intermediate spatial scale (site) and at the small- est scale (quadrat), and significant differences were only seen between sampling dates (Table 2). Most of the site differences regardless of season or sampling date were within the LA meadow rather than in the pristine $\mathrm{Sc}$ bed $(\mathrm{SNK}, \mathrm{p}<0.01)$, indicating a higher heterogeneity in this feature in the impacted meadow.

Leaf width showed significant differences at station and quadrat scales, while temporally significant differences were recorded only with season (Table 2). Concerning the differences between stations, $25 \%$ of them were significantly different at LA, compared to $>42 \%$ at $\mathrm{Sc}$, indicating a higher variability in the latter meadow (SNK, $\mathrm{p}<0.05$ ). 
Table 1. Posidonia oceanica shoot density comparison among locations, sites, stations and plots in 2 different seasons and on 2 different sampling dates using nested ANOVA. L: location; S: season; D: date of sampling; Si: site; St: station; Pl: plot; F: fixed factor; R: random factor. Significant values $(\alpha=0.05)$ in bold

\begin{tabular}{|c|c|c|c|c|c|}
\hline & \multirow[t]{2}{*}{ Effect } & \multirow[t]{2}{*}{$\mathrm{df}$} & \multicolumn{3}{|c|}{ Shoot density } \\
\hline & & & MS & $F$ & $\mathrm{p}$ \\
\hline $\mathrm{L}$ & $\mathrm{F}$ & 1 & 2076764 & 90.68 & 0.001 \\
\hline $\mathrm{S}$ & $\mathrm{F}$ & 1 & 44222 & 1.93 & 0.237 \\
\hline $\mathrm{L} \times \mathrm{S}$ & $\mathrm{F}$ & 1 & 20104 & 0.88 & 0.402 \\
\hline $\mathrm{D}(\mathrm{L} \times \mathrm{S})$ & $\mathrm{R}$ & 4 & 22902 & 0.72 & 0.589 \\
\hline $\operatorname{Si}(D(L \times S)$ & $\mathrm{R}$ & 16 & 31665 & 1.72 & 0.111 \\
\hline $\operatorname{St}(\operatorname{Si}(D(L \times S)))$ & $\mathrm{R}$ & 24 & 18394 & 2.47 & 0.001 \\
\hline $\operatorname{Pl}(\operatorname{St}(\operatorname{Si}(\mathrm{D}(\mathrm{L} \times \mathrm{S}))))$ & $\mathrm{R}$ & 96 & 7458 & 0.97 & 0.565 \\
\hline Error & & 144 & 7708 & & \\
\hline Cochran C & & & & 0.08 & 0.995 \\
\hline Transformation & & & & no & \\
\hline
\end{tabular}

Leaf surface showed significant differences only at the quadrat scale (Table 2). Significant differences between the dates of sampling were also evident (Table 2), with the first date in summer always greater in value than the second regardless of the meadow; the contrary was true during winter $(\mathrm{SNK}, \mathrm{p}<0.01)$.

Leaf biomass (Figs. 3 \& 4) varied significantly at the spatial scales of site and quadrat (Table 2) and on the temporal scale; it showed significant differences both with seasons and date of sampling. Regardless of the meadow, $\sim 75 \%$ of sites differed significantly from each other at the site-scale (SNK, p < 0.05), indicating the same degree of spatial heterogeneity. Components of variance calculated on each spatial scale (Fig. 5) indicated that most of the explainable shoot density variance was concentrated in the location and error (i.e. within-area scale or residual mean squares) factors. With respect to the main morphometric features, the error factor explained most of the

Table 2. Comparison among locations, sites, stations, plots and quadrats at 2 different seasons and 2 different sampling dates of Posidonia oceanica morphological and structural features using a nested ANOVA. L: location; S: season; D: date of sampling; Si: site; St: station; Pl: plot; Q: quadrats; F: fixed factor; R: random factor. Significant values ( $\alpha=0.05$ or 0.01 , when specified) in bold

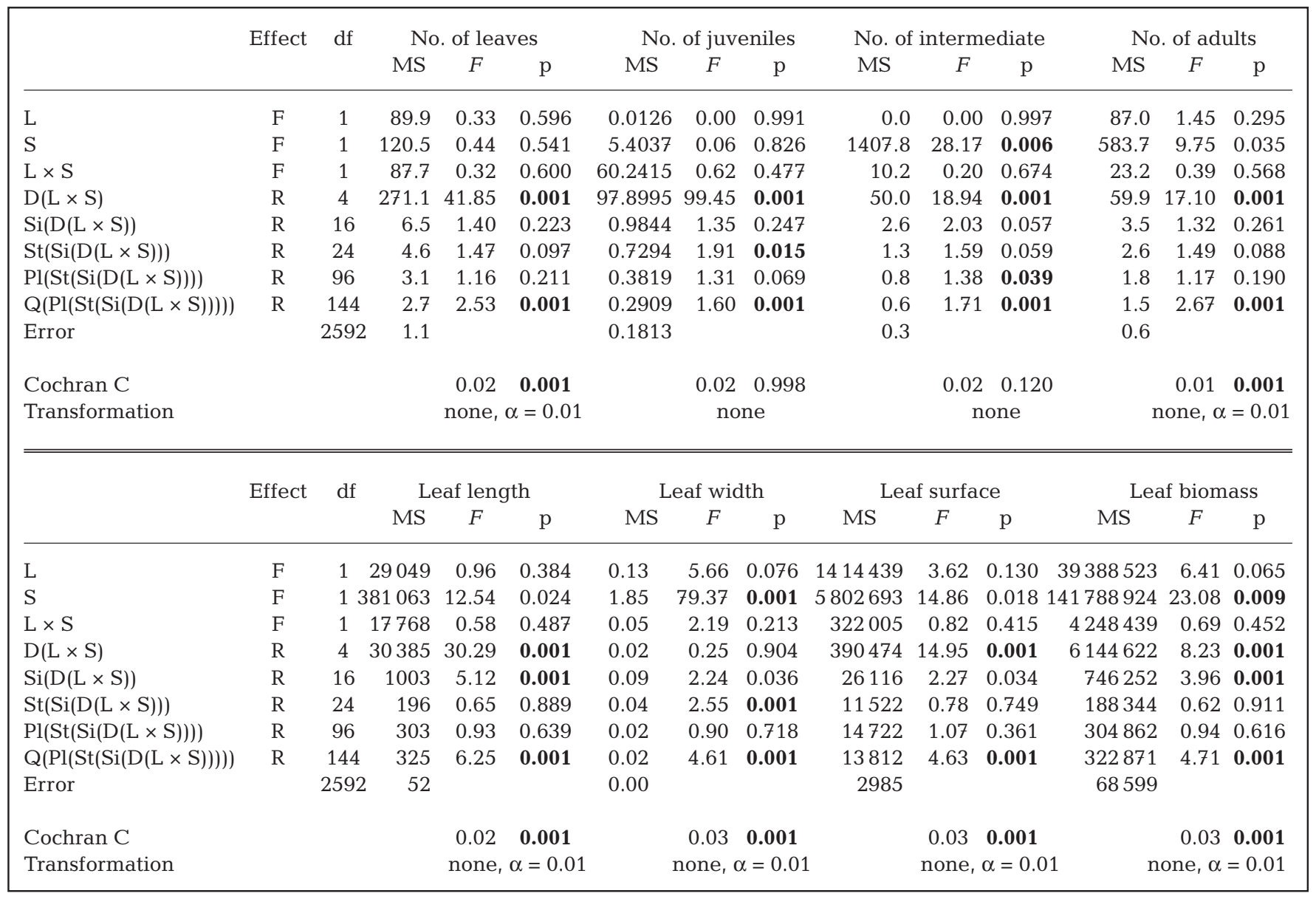



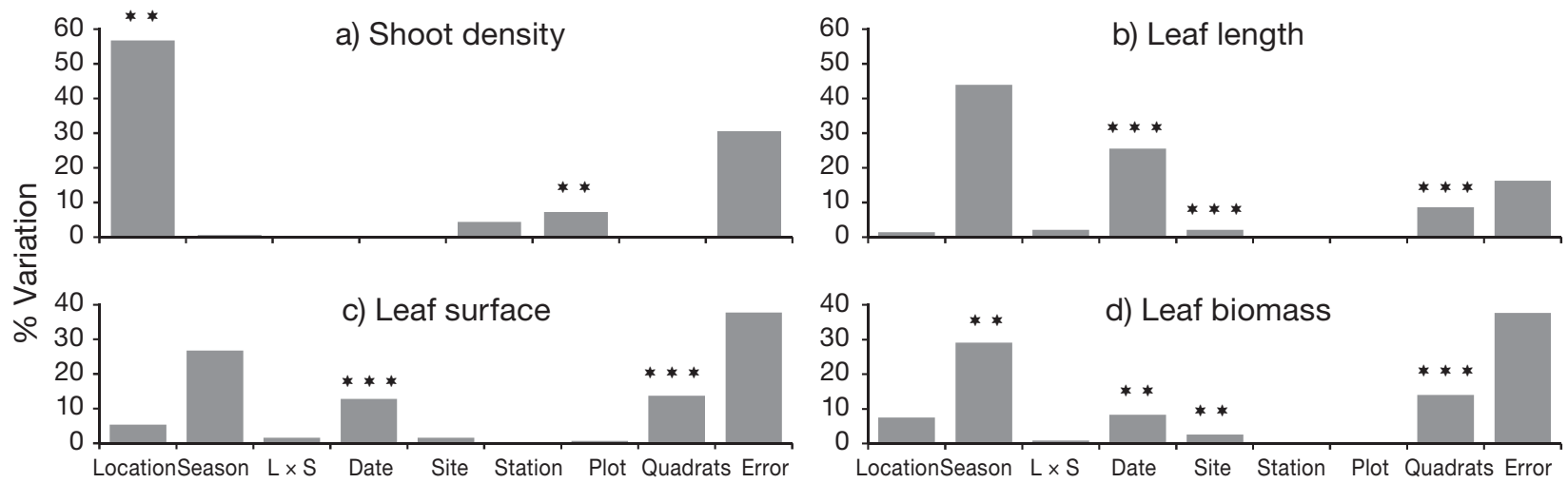

Fig. 5. Posidonia oceanica. Components of variance of the main descriptors of LA and Sc meadows at different spatial and temporal scales. Values are percentages of the total overall variation partitioned among scales. Negative variance components were converted to $0 . \mathrm{L} \times \mathrm{S}=$ interaction between location (L) and season (S). Significant differences: ${ }^{* *} \mathrm{p}<0.01$; ${ }^{* * *} \mathrm{p}<0.001$

variance observed, followed by the temporal scales (season and date of sampling). Also important was the percentage of variance explained by the quadrat scale (i.e. variance among shoots). Finally, the intermediate scales of site, station and plot, at least for the main plant features, were the least important source of variation, supporting a hypothesis that small-scale variability is dominant in these systems.

PERMANOVA was calculated excluding the total number of leaves from the calculations to avoid the bias of co-variation among the 3 leaf characteristics. There were significant differences in the variable associations both spatially (at the smaller scales of site and station) and temporally (between seasons and date of sampling; Table 3). For both meadows and for both seasons, differences existed between the sampling dates (pairwise comparisons, $\mathrm{p}_{\mathrm{MC}}<$

Table 3. Permutational multivariate analysis of variance of the differences among locations, sites, stations and plots in 2 different seasons and on 2 different dates of sampling of the main Posidonia oceanica features (except total number of leaves per shoot). L: location; S: season; D: date of sampling; Si: site; St: station; $\mathrm{Pl}$ : plot; $\mathrm{p}_{\text {perm }}$ : probability values from permutations; $\mathrm{p}_{\mathrm{MC}}$ : probability values estimated by Monte

Carlo simulations. Significant values $(\alpha=0.05)$ in bold

\begin{tabular}{|lcrrrrrr|}
\hline Source & df & SS & \multicolumn{4}{c|}{ MS Pseudo- } \\
& & \multicolumn{5}{c|}{$\mathrm{p}_{\text {perm }}$} & $\mathrm{p}_{\mathrm{MC}}$ \\
& & & & & & \\
$\mathrm{L}$ & 1 & 221.8 & 221.8 & 2.2 & 0.143 & 0.116 \\
$\mathrm{~S}$ & 1 & 830.3 & 830.3 & 8.4 & $\mathbf{0 . 0 1 1}$ & $\mathbf{0 . 0 0 2}$ \\
$\mathrm{L} \times \mathrm{S}$ & 1 & 58.3 & 58.3 & 0.6 & 0.641 & 0.651 \\
$\mathrm{D}(\mathrm{L} \times \mathrm{S})$ & 4 & 395.8 & 98.9 & 12.1 & $\mathbf{0 . 0 0 1}$ & $\mathbf{0 . 0 0 1}$ \\
$\mathrm{Si}(\mathrm{D}(\mathrm{L} \times \mathrm{S}))$ & 16 & 130.7 & 8.2 & 2.0 & $\mathbf{0 . 0 0 6}$ & $\mathbf{0 . 0 2 6}$ \\
$\mathrm{St}(\operatorname{Si}(\mathrm{D}(\mathrm{L} \times \mathrm{S})))$ & 24 & 96.5 & 4.0 & 1.7 & $\mathbf{0 . 0 0 3}$ & $\mathbf{0 . 0 0 1}$ \\
$\mathrm{Pl}(\mathrm{St}(\operatorname{Si}(\mathrm{D}(\mathrm{L} \times \mathrm{S}))))$ & 96 & 227.9 & 2.4 & 1.0 & 0.422 & 0.419 \\
$\operatorname{Residuals}$ & 144 & 334.7 & 2.3 & & & \\
\hline
\end{tabular}

0.001; Table 4). The nMDS (Fig. 6) gives a clear pattern of the differences shown by PERMANOVA. Axis 1 represents the seasonal variation, while Axis 2 represents the sampling date variation. The Pearson's correlations (Table 5) indicate the contribution of each single variable to this plot arrangement. Leaf surface, leaf length, total leaf biomass and the number of adult leaves are clearly the drivers for the separation of the 2 seasons, increasing in summer and decreasing in winter. The opposite is true for leaf

Table 4. Pairwise comparison from the multivariate analysis of Posidonia oceanica features. Significant values $(\alpha=0.05)$ in bold. LA: Lacco Ameno; Sc: Scarrupata; A, B, C: sites; 1, 2: stations; Sum: summer; Win: winter; fir and sec: first and second dates of sampling; $\mathrm{p}_{\text {perm: }}$ probability values from permutations; $\mathrm{p}_{\mathrm{MC}}$ : probability values estimated by Monte Carlo simulations; perms: number of permutations made

\begin{tabular}{|lcccc|}
\hline Source & Groups & $p_{\text {perm }}$ & Perms & $p_{\text {MC }}$ \\
\hline LA Sum & fir, sec & 0.105 & 10 & $\mathbf{0 . 0 0 1}$ \\
LA Win & fir, sec & 0.095 & 10 & $\mathbf{0 . 0 0 1}$ \\
Sc Sum & fir, sec & 0.101 & 10 & $\mathbf{0 . 0 0 1}$ \\
Sc Win & fir, sec & 0.105 & 10 & $\mathbf{0 . 0 0 2}$ \\
\hline LA Win fir & A, B & 0.328 & 3 & 0.096 \\
& A, C & 0.347 & 3 & 0.092 \\
& B, C & 0.335 & 3 & $\mathbf{0 . 0 3 4}$ \\
Sc Win fir & A, B & 0.331 & 3 & 0.225 \\
& A, C & 0.328 & 3 & $\mathbf{0 . 0 3 0}$ \\
\hline LA Sum sec A & 1,2 & 0.101 & 10 & 0.307 \\
Sc Win fir B & 1,2 & 0.099 & 10 & $\mathbf{0 . 0 2 4}$ \\
Sc Win sec B & 1,2 & 0.194 & 10 & $\mathbf{0 . 0 4 0}$ \\
Sc Win sec C & 1,2 & 0.106 & 10 & $\mathbf{0 . 0 1 3}$ \\
\hline
\end{tabular}




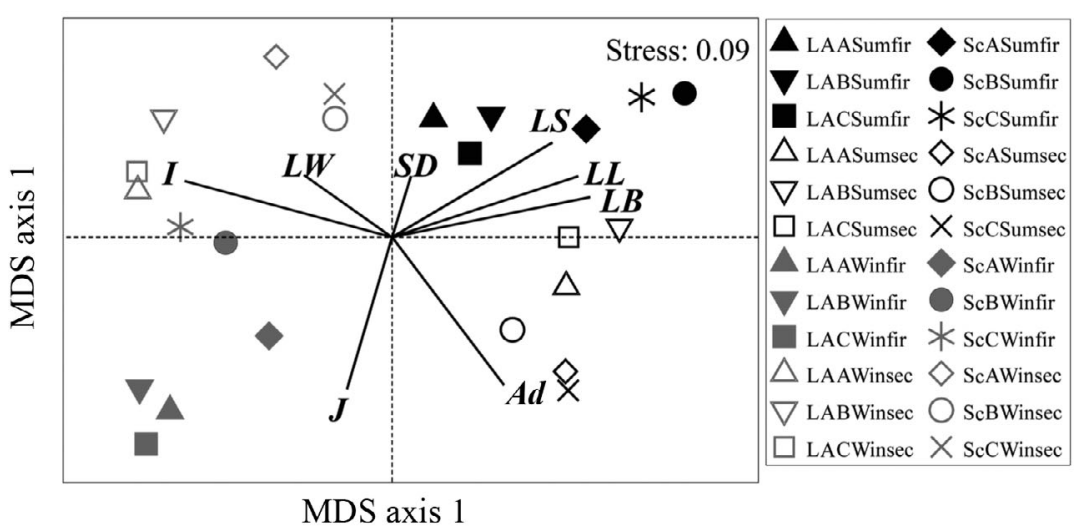

Fig. 6. Non-metric multidimensional scaling (nMDS) ordination biplot on the basis of Euclidean distances of centroids and Pearson's correlations of plant features with the first 2 nMDS axes. LS: leaf surface; LL: leaf length; LB: leaf biomass; LW: leaf width; SD: shoot density; Ad: adult; J: juvenile; I: intermediate; LA: Lacco Ameno; Sc: Scarrupata; A, B, C: sites; Sum: summer; Win: winter; fir and sec: first and second dates of sampling (e.g. LAASumfir = Lacco Ameno, site A, Summer, first date)

Table 5. Pearson's correlation values of the Posidonia oceanica features with the 2 main nMDS axes (MDS 1 and MDS 2). LL: leaf length; LW: leaf width; LS: leaf surface; SD: shoot density; LB: leaf biomass; J: juvenile; I: intermediate; Ad: adult

\begin{tabular}{|c|c|c|c|c|c|c|c|c|}
\hline & LL & LW & LS & $\mathrm{SD}$ & LB & $\mathrm{J}$ & I & $\mathrm{Ad}$ \\
\hline MDS1 & 0.93 & -0.27 & 0.91 & 0.12 & 0.93 & -0.05 & -0.78 & 0.67 \\
\hline MDS2 & 0.22 & 0.38 & 0.27 & 0.42 & 0.20 & -0.82 & 0.39 & -0.50 \\
\hline
\end{tabular}

ing generalizations or highlighting differences based on features that define the habitat itself. Using an appropriate spatial sampling design that considers the natural variability of the biotic descriptors avoids this problem (Wiens 1989, Levin 1992, Balestri et al. 2003, Montefalcone et al. 2008a). Failing to consider the appropriate spatial scale may result in an inadequate and unrepresentative description of the state of a particular meadow. Furthermore, an erroneous selection of the spatial and temporal scales may inhibit comparison among meadows because differences may be confused with natural variation (Balestri et al. 2003). Thus, the hypothesis tested and discussed herein, as supported by previous papers (Balestri et al. 2003, Borg et al. 2005, 2006, Zupo et al. 2006a,b, Montefalcone et al. 2008a), was that heterogeneity across scales and variables would increase as disturbance level increases. To test this hypothesis, we asked whether and how plant features varied within and between 2 distinct meadows across several spatial and temporal scales.

width and the number of the intermediate leaves, which increased in winter. The number of juvenile leaves was not related to seasonal variation, but when coupled with the number of adult leaves, it appeared to be important in explaining the separation seen between the dates of sampling. Contrary to the ANOVA interpretation, shoot density did not influence this relationship because of its low correlative value.

\section{DISCUSSION}

The importance of using $>1$ spatial scale when studying complex habitat has been widely discussed by many authors (e.g. Wiens et al. 1986, Wiens 1989, Underwood 1991, Levin 1992, Underwood \& Chapman 1996, 1998, Fraschetti et al. 2005). Among complex habitats, seagrasses in general — and Posidonia oceanica in particular - could be considered one of the most heterogeneous in the Mediterranean Sea. The problem when approaching a study on the ecology of a habitat engineer species such as this is mak-
The few authors who have investigated multispatial-scale variability of the descriptors in Posidonia oceanica meadows (Balestri et al. 2003, Borg et al. 2005, 2006, Montefalcone et al. 2008a) showed that spatial variability is highest at the smallest scales (meters to centimeters) of most of the considered variables. The present study also provides evidence on the variability of most measured plant parameters between the meadows.

Shoot density has been widely used by many authors as a descriptor of the ecological status of a meadow (e.g. Buia et al. 2004, Pergent-Martini et al. 2005, Lopez y Royo et al. 2010b). Mean shoot density values in the pristine meadows off Sc were almost twice those found at LA. The density values at LA are in the low range of a disturbed meadow, according to the classification of Pergent-Martini \& Pergent (1996), while the values at Sc are in the range of a normal density, indicating a meadow in equilibrium for the reference depth. The differences in shoot density recorded indicate that the 2 meadows were structurally different, a result consistent with previous studies that showed that LA is typical of a dis- 
turbed meadow (Guidetti \& Fabiano 2000). Comparatively, the differences observed at the intermediate scale (10s of meters) might be explained by withinmeadow heterogeneity stemming from local factors, such as bottom morphology and topographic complexity and/or nutrient availability (Balestri et al. 2003, Zupo et al. 2006b).

Balestri et al. (2003) found significant shoot density variability at the scale of 100 s of meters using the same approach adopted in the present study. Unfortunately, neither physical (e.g. particle size) nor nutrient data of the bottom were available for the present work; however, our results suggest that these factors may potentially explain the observed variability in shoot density, as supported by others (Zupo et al. 2006a,b, Giovannetti et al. 2008). The importance of small-scale/within-bed variability has not been well studied in the past because (1) sampling designs did not allow this variation to be isolated and (2) researchers have focused on depth differences in shoot density (as well as other plant features). Thus, although shoot density is considered a good indicator of the status of seagrass meadows, our findings demonstrate the importance of not underestimating smallscale variability and how this might potentially influence how shoot density differences are interpreted, especially in instances in which sampling designs do not include the appropriate scale(s) to identify spatial variability. For example, when shoot density is considered together with other plant variables, the discriminatory value between 2 meadows seems masked by other variables, as was evident in the PERMANOVA results and the nMDS. The reason for this may be the lack of temporal variation in shoot density was not unexpected because Posidonia oceanica, unlike other seagrass species, does not undergo large seasonal changes in spatial coverage or shoot density (except in rare events of heavy storms) (Marbà et al. 1996).

None of the other morphometric features measured in the present study presented any significant variability at location scale, i.e. between meadows, but were all highly variable at the smallest scale of quadrat (10s of centimeters). This is an important finding because the small-scale variability, if not appropriately considered, would lead to erroneous interpretation and subsequently inappropriate management decisions, above all because some of these features have been used in several monitoring programs to evaluate the status of meadows (PergentMartini et al. 2005). Moreover, most of the measured parameters displayed multi-spatial scales of variation from 10 s of centimeters to 100 s of meters. Also, the reduced shoot density in the LA meadow was not mirrored by lower leaf biomass or surface, suggesting that between-meadow differences were more important than any morphological variability that might exist. This result does not support our hypothesis that the more disturbed LA meadow would have greater small-scale variability. This conclusion demonstrates the importance of local factors and their influence on larger-scale patterns in complex habitat. In similar studies on Posidonia oceanica (Balestri et al. 2003, Borg et al. 2005, Montefalcone et al. 2008a, Castejon-Silvo \& Terrados 2012), the same high variability seen in the present study was observed at the smallest scales. According to Balestri et al. (2003), these studies do not indicate the factors determining these patterns, nor does the simple application of hierarchical sampling design indicate why these spatial patterns exist (Underwood 1997), but several hypotheses could be formulated by observing patterns of morphology of $P$. oceanica. Variations at the largest scale (between meadows, several kilometers apart) might reflect differences in the ecological setting at the localities, such as wave exposure, substrate sediment characteristics and/or biological impacts, such as grazing pressure or anthropogenic impacts. Factors such as physical disturbance, topographic complexity and nutrient availability (Zupo et al. 2006a,b) might operate on smaller scales to modify morphological plant variables. Variations observed at the smallest scales ( $\mathrm{cm}$ to $\mathrm{m}$ ) are more difficult to explain, but they could be attributable to undefined nested components of variation (Underwood 1997) and/or differences in the microhabitat (Balestri et al. 2003, Zupo et al. 2006a,b). The results obtained in the present study confirm the high morphological plasticity of $P$. oceanica in response to a range of environmental conditions, supporting the need for a more rigorous approach when studying ecological relationships at large scales or over long terms in this ecosystem.

Plant features, such as leaf width and biomass, varied with season and above all with the date of sampling, although our sampling dates were within the same putative season and no more than 2 mo apart from each other. The causes for these differences are mainly related to the cyclic vegetative growth of the plant (e.g. Pirc 1985, Buia et al. 1992) and to physical conditions that, for a few of the studied features, are crucial. For example, differences observed from one date of sampling to another (e.g. in leaf length) depended on the influence of water movement that favored the detachment of apical brown tissue from the leaves. 
Our results illustrate the importance of considering temporal scales as well as spatial scales. In fact, for monitoring purposes, it is important that samples from different meadows are collected during comparable dates within a season to avoid type II statistical errors due mainly to natural differences that could mask differences due to actual ecological settings and effects of disturbances.

In conclusion, in the present study, both the high morphometric plasticity and the spatio-temporal variability of Posidonia oceanica have been highlighted despite the ecological status of the meadows. The importance of considering comparable dates of sampling into sampling programs was also shown because of the strong dependence of many plant features on the particular month of sampling.

Thus, the standardization of a hierarchical design that considers several spatial scales at one time must be considered in the future monitoring programs as an optimal management practice, above all after the adoption of the EU Water Framework Directive. In this context, it is important that the application of a biological index made for a rapid assessment of the ecological status of a meadow should derive from a sampling design comparable to that used in different Mediterranean areas and monitoring programs. Above all, this index should consider the intrinsic variability of the plant at different spatial scales (as shown here), thus increasing the usefulness of the index in the entire basin meadows because the indices made so far are not always appropriate for all meadows.

Acknowledgements. We thank the entire staff of the benthic ecology group of the Stazione Zoologica at Villa Dohrn (Ischia) for support during the field and laboratory work. We thank in particular Cap. V. Rando and B. Iacono for thorough support during sampling at sea as well as the colleagues and students who helped with the field work: M. Lorenti, I. Castejon-Silvo, M. A. Iannotta, G. Califano, S. Signorelli, G. Procaccini and M. C. Buia. M. Cigliano and L. Villano helped with the morphological analysis. We are indebted to L. Benedetti-Cecchi and M. J. Anderson for advice in planning the hierarchical sampling design and statistical analyses, to G. Paterson for constant advice and support for the $\mathrm{PhD}$ thesis of C.V. and to F. Pititto for providing the figure of the sampling area. We also thank 3 anonymous referees for their advice and critical reviews. This work is part of an Open University $\mathrm{PhD}$ thesis funded by the Stazione Zoologica Anton Dohrn of Naples.

\section{LITERATURE CITED}

Anderson MJ (2001a) A new method for non-parametric multivariate analysis of variance. Austral Ecol 26:32-46 Anderson MJ (2001b) Permutation tests for univariate or multivariate analysis of variance and regression. Can J Fish Aquat Sci 58:626-639

Anderson MJ, Willis TJ (2003) Canonical analysis of principal coordinates: a useful method of constrained ordination for ecology. Ecology 84:511-525

Balata D, Nesti U, Piazzi L, Cinelli F (2007) Patterns of spatial variability of seagrass epiphytes in the north-west Mediterranean Sea. Mar Biol 151:2025-2035

- Balestri E, Cinelli F, Lardicci C (2003) Spatial variation in Posidonia oceanica structural, morphological and dynamic features in a northwestern Mediterranean coastal area: a multi-scale analysis. Mar Ecol Prog Ser 250:51-60

Borg JA, Attrill MJ, Rowden AA, Schembri PJ, Jones MB (2005) Architectural characteristics of two bed types of the seagrass Posidonia oceanica over different spatial scales. Estuar Coast Shelf Sci 62:667-678

Borg JA, Rowden AA, Attrill MJ, Schembri PJ, Jones MB (2006) Wanted dead or alive: high diversity of macroinvertebrates associated with living and 'dead' Posidonia oceanica matte. Mar Biol 149:667-677

Boström C, Jackson EL, Simenstad CA (2006) Seagrass landscapes and their effects on associated fauna: a review. Estuar Coast Shelf Sci 68:383-403

Boudouresque CF, Bernard G, Pergent G, Shili A, Verlaque M (2009) Regression of Mediterranean seagrasses caused by natural processes and anthropogenic disturbances and stress: a critical review. Bot Mar 52:395-418

> Buia MC, Zupo V, Mazzella L (1992) Primary production and growth dynamics in Posidonia oceanica. PSZN I Mar Ecol 13:2-16

Buia MC, Gambi MC, Lorenti M, Dappiano M, Zupo V (2003) Aggiornamento sulla distribuzione e sullo stato ambientale dei sistemi a fanerogame marine (Posidonia oceanica e Cymodocea nodosa) delle isole Flegree. In: Gambi MC, De Lauro M, Jannuzzi F (eds) Ambiente marino costiero e territorio delle isole Flegree (Ischia Procida Vivara - Golfo di Napoli). Risultati di uno studio multidisciplinare. Acc Sc Lett Arti Napoli, Mem Soc Fis Mat, Napoli, Napoli, p 163-186

Buia MC, Gambi MC, Dappiano M (2004) Seagrass systems. Biol Mar Medit 11:133-183

> Castejon-Silvo I, Terrados J (2012) Patterns of spatial variation of nutrient content, epiphyte load and shoot size of Posidonia oceanica seagrass meadows (Mediterranean Sea). Mar Ecol 33:165-175

Colantoni P, Gallignani P, Fresi E, Cinelli F (1982) Patterns of Posidonia oceanica (L.) Delile beds around the Island of Ischia (Gulf of Naples) and in adjacent waters. PSZN I Mar Ecol 3:53-74

Dayton P, Tegner M (1984) The importance of scale in community ecology: a kelp forest example with terrestrial analogs. In: Price P, Slobodchikoff C, Gaud W (eds) A new ecology: novel approaches to interactive systems. John Wiley \& Sons, New York, NY, p 457-481

> Fraschetti S, Terlizzi A, Benedetti-Cecchi L (2005) Patterns of distribution of marine assemblages from rocky shores: evidence of relevant scales of variation. Mar Ecol Prog Ser 296:13-29

Frost T, DeAngelis D, Bartell S, Hall D, Hurlbert S (1988) Scale in the design and interpretation of aquatic community research. In: Carpenter S (ed) Complex interactions in lake communities. Springer, New York, NY, p 229-258

Gambi MC, Buia MC (2003) Sintesi delle conoscenze sugli aspetti biologici ed ecologici dei popolamenti marini delle isole Flegree. In: Gambi MC, De Lauro M, Jannuzzi 
F (eds) Ambiente marino costiero e territorio delle isole Flegree (Ischia, Procida, Vivara, Golfo di Napoli). Acc Sc Lett Arti Napoli, Mem Soc Fis Mat, Napoli, p 111-132

Gambi MC, Lorenti M, Russo GF, Scipione MB, Zupo V (1992) Depth and seasonal distribution of some groups of the vagile fauna of the Posidonia oceanica leaf stratum: structural and trophic analyses. Mar Ecol Prog Ser 13:17-39

- Giovannetti E, Lasagna R, Montefalcone M, Bianchi CN, Albertelli G, Morri C (2008) Inconsistent responses to substratum nature in Posidonia oceanica meadows: an integration through complexity levels? Chem Ecol 24: 83-91

> González-Correa JM, Bayle Sempere JT, Sánchez-Jerez P, Valle C (2007) Posidonia oceanica meadows are not declining globally. Analysis of population dynamics in marine protected areas of the Mediterranean Sea. Mar Ecol Prog Ser 336:111-119

Guidetti P, Fabiano M (2000) The use of lepidochronology to assess the impact of terrigenous discharges on the primary leaf production of the Mediterranean seagrass Posidonia oceanica. Mar Pollut Bull 40:449-453

Kendrick GA, Duarte CM, Marbà N (2005) Clonality in seagrasses, emergent properties and seagrass landscapes. Mar Ecol Prog Ser 290:291-296

Kotliar NB, Wiens JA (1990) Multiple scales of patchiness and patch structure: a hierarchical framework for the study of heterogeneity. Oikos 59:253-260

> Leriche A, Pasqualini V, Boudouresque CF, Bernard G, Bonhomme P, Clabaut P, Denis J (2006) Spatial, temporal and structural variations of a Posidonia oceanica seagrass meadow facing human activities. Aquat Bot 84:287-293

- Levin SA (1992) The problem of pattern and scale in ecology. Ecology 73:1943-1967

Lopez y Royo C, Casazza G, Pergent-Martini C, Pergent G (2010a) A biotic index using the seagrass Posidonia oceanica (BiPo), to evaluate ecological status of coastal waters. Ecol Indic 10:380-389

- Lopez y Royo C, Pergent G, Pergent-Martini C, Casazza G (2010b) Seagrass (Posidonia oceanica) monitoring in western Mediterranean: implications for management and conservation. Environ Monit Assess 171:365-380

> Lorenti M, Buia MC, Di Martino V, Modigh M (2005) Occurrence of mucous aggregates and their impact on Posidonia oceanica beds. Sci Total Environ 353:369-379

- Marbà N, Cebrian J, Enriquez S, Duarte CM (1996) Growth patterns of Western Mediterranean seagrasses: speciesspecific responses to seasonal forcing. Mar Ecol Prog Ser 133:203-215

Mazzella L, Scipione MB, Buia MC (1989) Spatio-temporal distribution of algal and animal communities in a Posidonia oceanica meadow. PSZN I Mar Ecol 10:107-129

Mazzella L, Buia M, Gambi M, Lorenti M, Russo G, Scipione M, Zupo V (1992) Plant-animal trophic relationships in the Posidonia oceanica ecosystem of the Mediterranean Sea: a review. In: John DM, Hawkins SJ, Price JH (eds) Plant-animal interactions in the marine benthos. Clarendon Press, Oxford, p 165-187

> McArdle BH, Anderson MJ (2001) Fitting multivariate models to community data: a comment on distance-based redundancy. Ecology 82:290-297

> Milazzo M, Badalamenti F, Ceccherelli G, Chemello R (2004) Boat anchoring on Posidonia oceanica beds in a marine protected area (Italy, western Mediterranean): effect of anchor types in different anchoring stages. J Exp Mar Biol Ecol 299:51-62
Montefalcone M, Amigoni E, Bianchi CN, Morri C, Peirano A, Albertelli G (2008a) Multiscale lepidochronological analysis of Posidonia oceanica (L.) Delile rhizome production in a northwestern Mediterranean coastal area. Chem Ecol 24:93-99

Montefalcone M, Chiantore M, Lanzone A, Morri C, Albertelli G, Bianchi CN (2008b) BACI design reveals the decline of the seagrass Posidonia oceanica induced by anchoring. Mar Pollut Bull 56:1637-1645

> Montefalcone M, Albertelli G, Morri C, Parravicini V, Bianchi CN (2009) Legal protection is not enough: Posidonia oceanica in marine protected areas are not healthier than those in unprotected areas of the northwest Mediterranean Sea. Mar Pollut Bull 58:515-519

- Orth RJ, Carruthers TJB, Dennison WC, Duarte CM and others (2006) A global crisis for seagrass ecosystems. Bioscience 56:987-996

> Pardi G, Piazzi L, Balata D, Papi I, Cinelli F, Benedetti-Cecchi L (2006) Spatial variability of Posidonia oceanica (L.) Delile epiphytes around the mainland and the islands of Sicily (Mediterranean Sea). Mar Ecol 27:397-403

Pergent-Martini C, Pergent G (1996) Spatio-temporal dynamics of Posidonia oceanica beds near a sewage outfall (Mediterranean-France). In: Kuo J, Phillips RC, Walker DI, Kirkman H (eds) Seagrass Biol Int Workshop. Rottnest Island (Western Australia), p 299-236

> Pergent-Martini C, Leoni V, Pasqualini V, Ardizzone GD and others (2005) Descriptors of Posidonia oceanica meadows: use and application. Ecol Indic 5:213-230

> Piazzi L, Balata D, Cinelli F, Benedetti-Cecchi L (2004) Patterns of spatial variability in epiphytes of Posidonia oceanica. Differences between a disturbed and two reference locations. Aquat Bot 79:345-356

Pirc H (1985) Growth dynamics in Posidonia oceanica (L.) Delile. PSZNI Mar Ecol 6:141-165

Procaccini G, Buia M, Gambi M, Perez M, Pergent G, Pergent-Martini C, Romero J (2003) The seagrasses of the Western Mediterranean. In: Green E, Short F (eds) World atlas of seagrasses. University of California Press, Berkeley, CA, p 48-58

- Ruiz JM, Romero J (2003) Effects of disturbances caused by coastal constructions on spatial structures, growth dynamics and photosynthesis of the seagrass Posidonia oceanica. Mar Pollut Bull 46:1523-1533

> Ruiz JM, Boudouresque CF, Enriquez S (2009) Mediterranean seagrasses. Bot Mar 52:369-381

Underwood AJ (1991) Spatial and temporal problems with monitoring. In: Calow P, Petts GE (eds) Rivers handbook, Vol 2. Blackwell Scientific, Oxford, p 101-123

> Underwood AJ (1992) Beyond BACI: the detection of environmental impacts on populations in the real, but variable, world. J Exp Mar Biol Ecol 161:145-178

Underwood AJ (1997) Experiments in ecology: their logical design and interpretation using analysis of variance. Cambridge University Press, Cambridge

> Underwood AJ, Chapman MG (1996) Scales of spatial patterns of distribution of intertidal invertebrates. Oecologia 107:212-224

Underwood AJ, Chapman MG (1998) Spatial analyses of intertidal assemblages on sheltered rocky shores. Aust J Ecol 23:138-157

Vizzini S (2009) Analysis of the trophic role of Mediterranean seagrasses in marine coastal ecosystems: a review. Bot Mar 52:383-393

Waycott M, Duarte CM, Carruthers TJB, Orth RJ and others 
(2009) Accelerating loss of seagrasses across the globe threatens coastal ecosystems. Proc Natl Acad Sci USA 106:12377-12381

Wiens JA (1989) Spatial scaling in ecology. Funct Ecol 3: 385-397

Wiens J, Addicott J, Case T, Diamond J (1986) Overview: the importance of spatial and temporal scale in ecological investigations. In: Diamond J, Case TJ (eds) Community ecology. Harper \& Row, New York, NY, p 145-153

Zucco C (2003) Evoluzione urbanistico territoriale delle isole Flegree (Ischia, Procida e Vivara). In: Gambi M, De Lauro M, Jannuzzi F (eds) Ambiente marino costiero e

Editorial responsibility: Brant Touchette,

Elon, North Carolina, USA territorio delle isole Flegree (Ischia, Procida, Vivara, Golfo di Napoli), Vol 5. Acc Sc Lett Arti Napoli, Mem Soc Fis Mat, Napoli, p 303-395

Zupo V, Buia MC, Gambi MC, Lorenti M, Procaccini G (2006a) Temporal variations in the spatial distribution of shoot density in a Posidonia oceanica meadow and pattern of genetic diversity. Mar Ecol 27:328-338

Zupo V, Mazzella L, Buia MC, Gambi MC, Lorenti M, Scipione MB, Cancemi G (2006b) A small-scale analysis of the spatial structure of a Posidonia oceanica meadow off the Island of Ischia (Gulf of Naples, Italy): relationship with the seafloor morphology. Aquat Bot 84:101-109

Submitted: November 7, 2011; Accepted: June 15, 2012 Proofs received from author(s): July 23, 2012 